\title{
Muestras del estrofismo andalusí y su métrica según la poesía hebrea*
}

\section{Samplers of Andalusi Strofic and Metrics as Reflected by Hebrew Poetry}

\author{
José Martínez Delgado \\ Universidad de Granada
}

Las primeras muestras de poesía hebrea andalusí inspiradas en la métrica y figuras árabes datadas a mediados del siglo $\mathrm{X}$ en Córdoba adoptan la forma de musammat. El musammat hebreo presenta juegos estróficos y modificaciones métricas que, en realidad, no son aceptadas en la poesía hebrea inspirada en la métrica árabe clásica. Estas desviaciones se producen en toda la tradición literaria judía andalusí (siglos X-XII). En este artículo se han seleccionado y analizado varias muestras de musammat hebreos que reflejan este uso y, además, al contener un acróstico nos permiten identificar a su autor y época. Con ello, se intenta arrojar luz sobre dos premisas aceptadas actualmente. La primera postula que el estrofismo de la poesía andalusí tiene su origen en el musammat y, la segunda, que en la poesía hebrea andalusí se dan dos modelos métricos: el cuantitativo y el silábico.

Palabras clave: musammat; poesía estrófica; céjel; poesía árabe; poesía hebrea; al-Andalus.
The first samples of Andalusi Hebrew poetry inspired by the Arabic metric and figures in the $10^{\text {th }}$ century at Cordoba took the form of musammat. Hebrew musammat lends both strophic games and metric changes not tolerated in Hebrew poetry inspired by classical Arabic metrics. This phenomenon will occur throughout all the classical period of the Jews of Andalus ( $10^{\text {th }}-12^{\text {th }}$ centuries). I selected a sample of acrostic Hebrew musammat in order to show this use establishing their date and place. The aim of these samples is to shed some light on two premises currently accepted: the stanzaic structure of the Andalusi poetry is rooted in the musammat and the Hebrew poetry has two metrical models: quantitative and syllabic.

Key words: musammat; strophic poetry; zajal; Arabic poetry; Hebrew poetry: al-Andalus.

* Este trabajo se ha desarrollado dentro del marco del proyecto de investigación "Recuperación y estudio del legado lingüístico judeo-árabe de al-Andalus" (FFI201451818-P). 


\section{Introducción}

El siguiente análisis parte de dos premisas aceptadas entre la mayoría de los académicos: 1 . El estrofismo de la poesía andalusí tiene su origen en el musammat y 2. En la poesía hebrea andalusí hay dos modelos métricos: el cuantitativo y el silábico. La propuesta que se presenta en estas páginas es doble y pretende arrojar luz sobre ambas premisas.

\subsection{El estrofismo de la poesía andalusí tiene su origen en el musammaț: ${ }^{1}$}

Dentro del campo de la crítica literaria árabe, se entiende mayoritariamente en la actualidad que la musammat surge en Iraq a través de la ruptura de la monotonía de la qașìda mediante la introducción del uso de sammațāt en Irak a partir del siglo vIII. Este recurso consiste en generar secuencias fijas de tres (musammat murabba) o cuatro (musammat muhammas) rimas internas (ag்sām) dentro de los versos que siguen conservando la rima original (simt); es decir, la secuencia monorrima clásica aaaaa... derivó en bbb(b)a ccc(c)a ddd(d)a... También se afirma que los versos del musammat pudieron dar forma en Alandalus a partir del siglo $\mathrm{x}$ a las estrofas [aa] bbba ccca... del céjel y [a] bbbaa cccaa... del muwašša h. ${ }^{2}$ El principal escollo a esta teoría es la inexistencia de muestras de musammat árabe en Alandalus durante este período. Los motivos que explicarían esta ausencia pueden ser varios: pudieron ser composiciones de baja calidad; pudieron ser rechazados por los antólogos locales, muy puristas; o porque fue rápidamente suplantado por el nuevo género. ${ }^{3}$

Frente a esta escasez en árabe, encontramos toda una rica gama de posibilidades y usos en la poesía hebrea medieval compuesta en la

\footnotetext{
${ }^{1}$ Dado que el elenco bibliográfico sobre el origen y evolución del estrofismo andalusí es muy amplio y conocido, omitiré la reseña de su génesis y desarrollo. A los interesados remito a obras de referencia como las de Corriente, Poesía dialectal árabe y romance en Alandalús, pp. 70-121 y Schippers, "Secular Hebrew Poetry in Muslim Spain till 1225 - A General Overview with the New Tendencies, Problems", pp. 119-134. Para el uso del musammat en Alandalus véase Ferrando, "Andalusi musammat: Some Remarks on its Stanzaic and Metrical Structure”, pp. 78-89.

${ }^{2}$ Corriente, Poesía dialectal árabe, pp. 23-27.

${ }^{3}$ Corriente, Poesía dialectal árabe, pp. 80-81.
} 
península ibérica. De hecho, las primeras muestras de poesía hebrea andalusí, es decir, inspiradas en la métrica y figuras árabes (ca. 958), son compuestas por Dunaš ben Labrat en Córdoba adoptando la forma de musammat murabba ' $(b b b a$ ccca $d d d a$...) y manipulando la métrica clásica. Son dos composiciones consagradas como clásicas en la literatura hebrea de todos los tiempos, la primera en honor al famoso mecenas judío y médico del califa 'Abdarraḥmān III, Hasday ibn Šapruṭ Conoce, corazón mío, la sabiduría y el aún más famoso poema báquico que recitó en una reunión (muğălis) en presencia de Ḥasday ibn Šaprut Me dice: no duermas, bebe vino añejo. ${ }^{4}$

La poesía litúrgica hebrea palestina de época bizantina o piyyut antiguo muestra ya la existencia de una tradición rítmica de este tipo desde épocas anteriores a la poesía árabe. Esto suscitó la cuestión de si podía verse en las estructuras estróficas andalusíes, al menos en el caso de los judíos, una continuación directa de esta tradición. Parece que no, aunque puede suponerse que la recepción de estas formas les resultó fácil a los judíos en su poesía sagrada porque no suponían un nuevo punto de partida sino una continuación, con un renovado impulso considerable, de los métodos empleados por los antiguos. ${ }^{5}$

Si bien el género clásico es claro en estas composiciones de Dunaš ben Labrat, musammat murabba ' (bbba ccca ddda...), no puede decirse lo mismo de la métrica. La secuencia es idéntica en todos los segmentos: ${ }^{6}$ WSSSS y una rima generadora en -im. Aunque tradicional-

\footnotetext{
${ }^{4}$ La edición más reciente y crítica de Conoce, corazón mío, la sabiduría es la de SáenzBadillos en Tešubot de Dunaš ben Labraț. En cuanto a Me dice: no duermas, bebe vino añejo, recientemente se ha descubierto que en realidad pertenece a un panegírico mucho más largo en honor a Ḥasday ibn Šapruṭ y véase Elizur, "Ḥidušim bě-ḥeqer ha-širah wěha-piyyut", pp. 176-207.

${ }^{5}$ Véase Fleischer, "Mibnnim sțrofiyim me'ayin ezurim ba-piyyut ha-qadum”, pp. 194-240.

${ }^{6}$ En la métrica clásica se entiende que las sílabas se forman a partir de la reunión de dos o más letras. De esta manera, en árabe a la unión de dos letras se le denomina sabab (en adelante s), a la de tres letras en dos sílabas se denomina watid (en adelante w) mientras que la secuencia de cuatro o más letras se conoce como fāṣila. Los pies se originan a partir de la sucesión de dos o tres de estas sílabas. La combinación de unas y otras sílabas métricas produce hasta diez pies. Dos de ellos se componen de cinco letras فَعُوَنْ

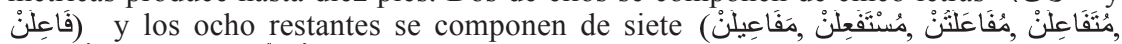

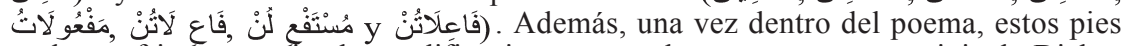
suelen sufrir una serie de modificaciones que alteran su aspecto original. Dichas modificaciones se conocen como ziḩâfăt o 'ilal dependiendo de su posición y constancia en la composición. Para una descripción teórica moderna sobre la métrica tradicional árabe véase Sánchez Sancha, "Introducción exegética a la métrica tradicional árabe", pp. 47-173.
} 
mente se le viene catalogando como tawīl (en hebreo arok ), lo cierto es que no hay licencia clásica que permita el paso de una secuencia ws WSS a WS SSS o, si se prefiere, de fa ' $\bar{u}$-lun mafā- 'i-lun a fa ' $\bar{u}$-lun maf'ü-lun; de hecho, este último pie (SSS) no existe como tal en el catálogo de la ciencia métrica clásica ( 'ilm al- 'arūọ) sino que sólo puede ser resultado de una modificación. ${ }^{7}$

Sea lo que sea esta secuencia métrica, esta fórmula se consagró como clásica y así ha sido reproducida y empleada exclusivamente en el género musammat por los cuatro grandes poetas hebreos del siglo de oro (mediados del siglo XI - mediados del s. XII): Šěmu'el ibn Nagrela (993-1055), Šělomo ibn Gabirol (c.1020-c.1057), Moše ibn 'Ezra (c.1055-d.1135) y Yěhuda ha-Leví (c.1070-1141). Estos poetas respetarán y reproducirán esta secuencia innovada por Dunaš ben Labraț en el musammaț tal y como hacen con el 'arụ̣̈ clásico cuando componen casidas en hebreo.

1.2. En la poesía hebrea andalusi hay dos modelos métricos: el cuantitativo y el silábico

Además de la consolidación de la secuencia métrica wssss en este tipo de composiciones, el musammat es el único género que, al menos en la poesía redactada en hebreo, se presta a inusitados juegos estróficos y a otras modificaciones métricas no toleradas en la poesía hebrea inspirada en la métrica árabe clásica. ${ }^{8}$ Este fenómeno se va a producir durante toda la historia del judaísmo andalusí autóctono (ss. X-XII) y de esta manera he podido seleccionar musammat hebreos con el nombre de su autor en acróstico, garantizando que abarcan los dos siglos en los que se desarrolla la cultura judeoandalusí en un intento de ofrecer una secuencia evolutiva.

Tradicionalmente se entiende que tras la adaptación de la llamada «técnica cuantitativa» árabe ideada por Dunaš ben Labraț, se desarrolló como rechazo a ésta para la poesía litúrgica de los judíos andalusíes la

${ }^{7}$ Así, por ejemplo, en el metro hazağ puede aplicarse una modificación (zihăâf) sobre el pie original wss del tipo harm (eliminación de la mìm de mafấ- $\mathfrak{l}$-lun) para obtener el pie sss.

${ }^{8}$ Para el uso del 'arūẹ clásico véase Martínez Delgado, "El uso de la métrica árabe en la obra Ben Tehillim de Samuel ibn Nagrela", pp. 263-294. 
que se viene denominando «técnica silábica», heredera del modelo románico. ${ }^{9}$

A partir de esta concepción se originaron dos teorías sobre la evolución de este modelo. Por un lado J. Yahalom defendió que esta métrica hebrea no era oriunda de Alandalus, sino oriental, y aunque aceptaba que su emergencia se produjo a mediados del siglo $\mathrm{x}$, reivindicaba que se originó por influencia del árabe pero tendiendo al modelo silábico debido a la pronunciación babilónica del hebreo. De oriente se expandiría por el mediterráneo hasta llegar a Alandalus quedando reservada para la poesía secular y empleándose junto con el modelo tradicional acentual, como en el caso de Měnahem ben Saruq (c.910-d.960). ${ }^{10}$ Siendo así, sería más fácil entender que el hallazgo de

\footnotetext{
${ }^{9}$ Así desde Fleischer, "Contributions hébraïques a une meilleure compréhension de quelques aspects de la poésie européenne du haut moyen age", pp. 815-866.

${ }^{10}$ Según Fleischer, en la primera mitad del siglo x ya se producía poesía secular en Alandalus y es posible que en este aspecto se adelantase a las metrópolis orientales. Desde un punto de vista formal era una poesía oriental o tradicional, aunque en su contexto histórico era la más moderna e innovadora entre las comunidades judías del islam. Por ejemplo, la endecha de Měnaḥem ben Saruq a la madre de Ḥasday ibn Šapruț, por su temática, recuerda más a un poeta árabe contemporáneo o a un poeta hebreo posterior a Dunaš ben Labraț, porque aun siendo una composición tradicional tiene una función social y un contexto que no es el tradicional. En la época de Měnaḥem ben Saruq (califato de 'Abdarraḥmān III) se componían auténticos panegíricos hebreos desconocidos en oriente. Según Fleischer, en estos panegíricos no hay influencia árabe, las composiciones carecen de métrica y la disposición de sus versos es la tradicional, ya que la rima única se emplea en hebreo desde tiempos antiguos y el uso de la cesura tampoco es indicio de influencia árabe. De hecho, el uso de la cesura en alguna composición es libre, por lo que no es obligatoria como en árabe; simplemente viene a romper la monotonía. Las composiciones de Mĕnaḥem ben Saruq confirman que la comunidad judía de Alandalus, desde una perspectiva social, estaba preparada para el cambio introducido por Dunaš ben Labraț. Por lo tanto la innovación de Dunaš ben Labrat se reduce únicamente al aspecto formal: la métrica. De hecho, los discípulos de Měnahem ben Saruq no dicen nada respecto a la estructura estrófica del poema ni a las imágenes árabes, tan sólo se centran en aspectos lingüísticos y métricos. La poesía religiosa es, según los materiales que conocemos, posterior a la secular. Aunque se importase piyyut de oriente es difícil imaginar que no hubiese poetas religiosos antes de la segunda mitad del siglo X, simplemente no tenemos noticias de ellos. Las más tempranas muestras son dos breves composiciones atribuidas a Mĕnahem ben Saruq sin innovación alguna y bajo la influencia total de oriente; ni siquiera aun bajo la de Sa'adia Ga'on (882-942). El hecho de que Měnaḥem ben Saruq firme como qațan 'pequeño' pueden hacernos pensar que son obras de juventud y que aun quizá no conociese la obra de Sa'adia Ga'on, Fleischer, "Lě-qadmuniot širatenu bi-Sfarad. 'Iyun ba-širim šel rabbi Měnaḥem ben Saruq", pp. 227-269. Un año más tarde, Fleischer dio a conocer nuevas muestras de panegíricos, demostrando que el uso del panegírico en hebreo era más frecuente de lo que pensábamos. En un poema dedicado al dayyan 'juez' de Córdoba Moše ben Ḥanok (-d.965, según la tradición fue hecho cautivo por el almirante
} 
Dunaš ben Labraț fuera bien acogido por los poetas de la época y se implantase como modelo a pesar de las críticas de los discípulos de Měnahem ben Saruq. ${ }^{11}$ La técnica silábica nunca sufrió crítica alguna; porque, a pesar de estar bajo influencia del árabe, recordaba y emulaba determinados pasajes bíblicos. Según esta teoría, este modelo sólo pudo originarse tras la adaptación y simplificación del modelo cuantitativo secular, aunque se reservó para la poesía religiosa. Se entiende que en este modelo silábico, a diferencia de los otros, el šěwa' móvil y compuesto siempre ocupan una posición fija. ${ }^{12}$ En contra de esta teoría se pronunció E. Fleischer, que defendió que ambos modelos métricos emergieron en Alandalus: a mediados del siglo x lo haría el cuantitativo y unos años o décadas después el silábico. El primero depende del modelo árabe y el segundo no. Se intentó demostrar además que Oriente no recibió estos modelos hasta el s. XI. ${ }^{13}$

Tradicionalmente se pensaba que este modelo silábico fue «adaptado» por los judíos italianos, dando lugar a la distinción entre el modelo silábico «gramatical» empleado en Alandalus y el modelo silábico «fonético» usado en Italia. Las diferencias entre ambos modelos radican en que el primero no computa las vocales breves ( ̌̌ěwa' móvil y compuesto y waw copulativo vocalizado), mientras que el segundo las entiende como vocales propiamente dichas. Sin embargo, T. Be'eri demostró que este modelo métrico andalusí no era exclusivo de la poesía religiosa y que además está muy relacionado con formas estróficas monorrimas o de dos rimas simétricas; en cuanto al modelo silábico italiano, según ella, no tendría nada que ver con el modelo andalusí sino que sería una adaptación de la poesía italiana. ${ }^{14}$

Ibn Rumāḥis en Bari y liberado por la comunidad judía de Córdoba), se incluye en acróstico el nombre del homenajeado e igualmente alude a él el pizmon que cierra las estrofas. Aunque la poesía anterior a Dunaš ben Labraț es formalmente idéntica a la poesía hebrea religiosa pre-andalusí, la gran novedad es temática: la alabanza al patrón, Fleischer, "Lětolědot širat ha-ḥol ha- “ibrit bi-Sfarad bě-re’šitah”, pp. 197-225.

${ }^{11}$ La crítica ha sido editada por Benavente Robles, Tešubot de los Discípulos de Měnahem contra Dunaš ben Labrat. Véase además el estudio de Sáenz-Badillos, "Los discípulos de Měnahem sobre la métrica hebrea", 421-431.

${ }_{12}$ Yahalom, "Re'šitah šel ha-šěqila ha-měduyyeqet ba-širah ha-'ibrit", pp. 25-61.

${ }^{13}$ Fleischer, "Běhinot bě-'aliyat šițot ha-šěqila ha-měduyaqot ba-šira ha-'ibrit", pp. 142-162.

${ }^{14}$ Be'eri, “The Phonetical-Syllabic Meter in Medieval Hebrew Poetry” (hebreo), pp. $50-70$. 


\section{Muestras seleccionadas}

Las siguientes muestras pretender cubrir los dos siglos de producción de poesía hebrea por los judíos de Alandalus (c.958-c.1141) y servirán para contrastar su métrica y estructura con las teorías expuestas en el epígrafe anterior. Todos los poemas seleccionados están firmados en acróstico, lo cual permite su datación. Para el siglo X emplearé un musammat de contenido religioso, según su acróstico, compuesto por Yișhaq ibn Qafrūn (léase Caprón): yagorti mippěne šamayim qone ${ }^{15}$ su interés radica en que se considera el primer poema andalusí que emplea el modelo silábico. Para el siglo XI recurriré al

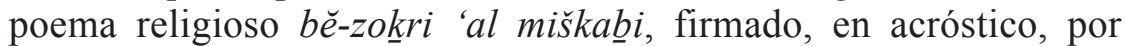
Yěhudah ibn Bal'am y también a Ibn Gabirol (c.1020-c.1057) para mostrar un uso «libre» de licencias métricas en poemas que pretenden ajustarse a la normativa clásica. Finalmente, para el siglo XII emplearé el poema «desde el mar» yo 'eș u-meqim bi-mrom šĕhaqim de Yěhudah ha-Leví (c.1070-1141). Según los editores, todos estos poemas son estróficos ('ezor) aunque carecen de metro (---_-/_-_-- ). De todos estos poemas existen traducciones al español a las que aludo en nota, salvo en el caso de Ibn Bal'am y dado que no conozco ninguna, es el único caso en el que ofrezco la mía propia.

\subsection{El siglo $X$}

Voy a omitir las primeras composiciones hebreas de este período que tienen forma de musammat por ser una respuesta (mu'árada) al poema de Ben Labrat y, salvo la licencia métrica antes mencionada (wSSSS), no presentan innovación alguna respecto al musammat tradicional. ${ }^{16}$ Para este período emplearé un musammat de contenido religioso, según su acróstico, compuesto por Yiṣ̣haq ibn Qafrūn (léase Caprón). El poema, una penitencial, se conoce como yagorti mippěne

${ }^{15}$ Es uno de los discípulos de Mĕnahemem ben Saruq que redactó las Těšubot (Réplicas) contra Dunaš ben Labraț y en las que, precisamente, se critica la adaptación de la métrica árabe al hebreo, véase Sáenz-Badillos, "Los discípulos de Mĕnahem sobre la métrica hebrea", pp. 421-431.

${ }^{16}$ Se trata de los poemas que introducen las Těšubot talmide Mĕnahem (Benavente Robles, Těšubot de los discípulos de Měnahem) y las Těšb bot talmid Dunaš (Varela Moreno, Těsub $\underline{b}$ ot de Yěhudit ben Šešet). 
šamayim qone y es un musammat murabba' con rima generadora en im. ${ }^{17}$ Se compone de 12 versos, divididos cada uno en 4 segmentos, es decir, un total de 48 segmentos. He ajustado la vocalización a la escansión que propongo: ${ }^{18}$

\begin{tabular}{|c|c|c|c|}
\hline שְׁפַָּתַי נֶאלַלִים & 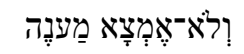 & שָשַמיִם קנֵנה & 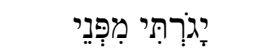 \\
\hline 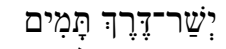 & 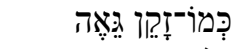 & חַסְסְדָּ אָזָ אֶרְרֶה & צָעִיר אָנַי וְנְכְאֵה \\
\hline צָעִיר אָנִי ְָיָמִים & וְלאץ-עוֹד אָדַבַּר & 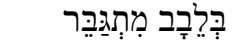 & 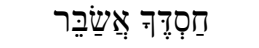 \\
\hline וְתַעַל לִי רַחמִים & 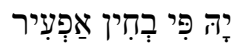 & 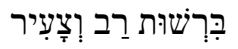 & 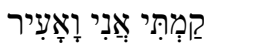 \\
\hline זיָּי צוּר עוֹלְמִים & יעיעזב חַלְך & 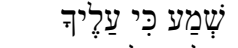 & 5 \\
\hline 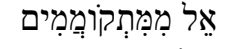 & 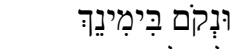 & אַל תַעעלַם עַינּך & 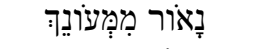 \\
\hline מְצוֹוִים וַחְרְמִים & ְְרַגְלִי הִצִיבְוּ & וְאִָּּי הִסְחְזיבוּ & קָדְשְּׁׁ הֶחרִיבוּ \\
\hline הָיינוּ יְתוֹמִים & כִּי אֵין לְנוּ אָב & וְלְבַּנוּ נִכְאָב & 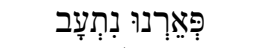 \\
\hline 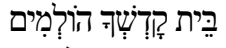 & 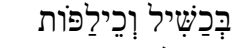 & 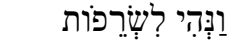 & ברדְנוּ לַחָרָּוֹת \\
\hline 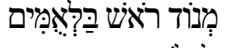 & 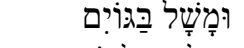 & נְפוּצִים וּבְזוּיִים & 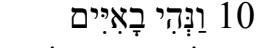 \\
\hline לִילוֹת וְגַם זימְים & וְעָלַי יִתְלַחשוּ & וְעַל גַּבּבּי חָרְש & 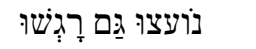 \\
\hline עַל כַַּּא רַחִמים & 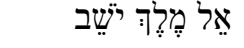 & 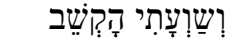 & 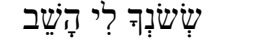 \\
\hline
\end{tabular}

Según los editores, el poema carece de metro (-----/--_-- ), sin embargo, al escandirlo según las normas del 'arūd clásico el resultado es el siguiente:

$\begin{array}{lllll} & \text { SSSSW } & \text { SSSSS } & \text { WSSSS } & \text { WSSSS } \\ & \text { SSWWS } & \text { SWSSS } & \text { WSSS } & \text { WSSSS } \\ \text { SSSWS } & \text { WSSSS } & \text { WSWS } & \text { SSWWS } \\ & \text { SSWSS }^{19} & \text { SSSWS } & \text { SSWSS } & \text { WSSSS } \\ & \text { WSSSS } & \text { WSSSS } & \text { SSSSS } & \text { SSSSS } \\ \text { SSSWS } & \text { SSSSS } & \text { SSSSS }^{20} & \text { SSSWS } \\ \text { SWSSS } & \text { WSSSS } & \text { WSSSS } & \text { WSSWS }\end{array}$

${ }^{17} \mathrm{El}$ texto hebreo fue originalmente publicado por Brody y Albretch, $\breve{S} a$ 'ar ha-šir The New-Hebrew School of Poets of the Spanish-Arabian Epoch, pp. 7-8. El poema fue traducido por Sáenz-Badillos y Targarona Borrás, Poetas hebreos de al-Andalus (siglos XXII), p. 39.

${ }^{18}$ En la siguiente codificación trato las guturales como quiescentes, como en árabe, sin que estas influyan o alteren la escansión. El resto de modificaciones las indico en nota.

${ }^{19} \mathrm{Si}$ no se aplica una licencia que altere la forma bíblica, tipo la eliminación de la vocal de la 'ayin, este segmento tendría que escandirse como SSWSSS con una sílaba más.

${ }^{20}$ La presencia del pronombre sufijo de $2^{\mathrm{a}}$ masc. sing. (7) provocaría la aparición de una sexta sílaba métrica en los tres primeros segmentos y que no está atestiguada en el resto del poema, lo que me lleva a leerlo en género femenino, más acorde con las secuencias métricas del resto de la composición. 


$\begin{array}{rllll} & \text { WSSSS } & \text { WSSSS } & \text { SSSSS } & \text { SSSWS } \\ 10 & \text { SSSSS } & \text { SWSSS } & \text { WSWSS } & \text { SSWSS } \\ & \text { SWSSS } & \text { WSSSS } & \text { WSSSS } & \text { WSSWS } \\ & \text { SSSSS } & \text { WSSSS } & \text { WSSSS } & \text { SSWSS } \\ & \text { WSSSS }^{21} & \text { WSSSS } & \text { SSSSS } & \text { SSSSS }\end{array}$

La primera conclusión que se extrae es que la técnica empleada permite que cada verso se parta en cuatro segmentos dotados de independencia métrica. Se ha perdido, por tanto, cualquier noción o rastro de 'arū $d$ y darb. ${ }^{22}$ Sobre esta concepción, la secuencia métrica más frecuente en estos 48 segmentos es, precisamente, la ideada por Dunaš ben Labraț, wssss, hasta 18 veces. A partir de ahí y aparentemente a partir de modificaciones (zihâafāt), el watid puede desplazarse ocupando todas las posiciones del segmento, es decir, SWSSS (4 veces), sSWSS (4 veces), sSSWs (5 veces), SSSSW (1 vez al comienzo del poema) e incluso llegar a desaparecer en una secuencia tipo sssss (hasta en 10 ocasiones); incluso puede aparecer dos veces en un mismo segmento, wSWSS (1 vez), wSSWs (2 veces) o sSwws ( 1 vez), además de la forma aislada wsws (1 vez). Lo cierto es que si se pretende aplicar la métrica clásica a esta composición, una secuencia tipo Wswss ( $1 \mathrm{vez})$ puede descomponerse en WS WSS o tawīl, wSSWs (2 veces) en wSS Ws o mustațil, sswws (2 veces) en SSW ws o rağaz, y WSWs (1 vez) en ws ws o mutaqārib. Si además, se contrasta con la métrica registrada en el cancionero de Ibn Quzmān y en la obra del Aššuštari, ${ }^{23}$ una secuencia tipo swsss (4 veces) puede descomponerse en sws ss o madīd y una tipo sswss (4 veces) en SSW ss o basīt..${ }^{24}$ Aun así, las secuencias más frecuentes son WSSSS (18 de 48) y sSSSS (10 de 48).

${ }^{21}$ Para obtener esta secuencia hay que hacer quiescente la nun de שְְִׁ.

${ }^{22}$ Según la normativa clásica, la sucesión de los pies da lugar al verso o bayt. El verso se compone de dos hemistiquios; el primer hemistiquio se conoce como sadr y el segundo como 'ăgz. Los primeros pies son denominados hašw o relleno, mientras que los últimos de cada hemistiquio tienen su propio nombre, 'arụ̣̈ en el caso del primero y darb en el del segundo.

${ }^{23}$ Véase Corriente, Gramática, métrica y texto del cancionero hispanoárabe de Aban Quzmán, especialmente las páginas 69-81 y ahora las notas a las cabeceras de los céjeles en la nueva edición de Corriente, Dīwān Ibn Quzmān Alqurtubī «Ișābat al-agrāạ fí dikikr al'a 'rāḍ» y Corriente, Poesía estrófica (cejeles y/o muwaššahăt) atribuida al místico granadino Ǎšššstari. Véase también Corriente, "Catorce cejeles de Ibn Zamrak y uno de Ibn Alxațīb (edición dialectológica, traducción y notas)”, pp. 1-33.

${ }^{24}$ Aunque véase más adelante el caso de Ibn Gabirol. 
De esta manera sólo restaría identificar las secuencias SSSSW (1 vez) y sssws (5 veces). La primera aparece al comienzo del poema y está tomada literalmente de Deuteronomio 9,19, por lo que podría quedar fuera de la métrica del poema, como veremos en los siguientes ejemplos. Finalmente, la secuencia sssws, relativamente frecuente, podría explicarse como sss ws (mustațīl) con el primer pie afectado por un harm, ${ }^{25}$ por lo que una secuencia original wss ws se convierte tras esta modificación en sSS wS. Esta trasgresión de la norma confirmaría la independencia métrica de los segmentos dentro de los versos. Además, seguramente las modificaciones pudieron usarse de manera casi libre, es decir, lo que en métrica clásica podía aplicarse al primer pie, podría hacerse también en el segundo, y así se originaría la secuencia WSsss usada por Dunaš ben Labraț.

Soy consciente de que desde esta perspectiva, en esta composición se pueden reconocer hasta seis metros distintos. No puedo determinar aun si se trata de un experimento del poeta en busca de una composición polimétrica, si es resultado de las modificaciones resultantes de la adaptación local del 'arụ̄̂ clásico o si simplemente está ensayando con poco acierto. Aunque visto así, aquí habría 'arūd, y algunas de estas secuencias las emplean Ibn Quzman o Aššuštari aunque de manera mucho más consistente. En cuanto al metro dominante me inclino por un mustațīl modificado, siendo su forma más frecuente wssss. ${ }^{26}$

Por esta época, quizá tras el asalto de Córdoba por las tropas bereberes (julio de 1013) emplea esta misma secuencia (WSSSS) en un musammat el primer poeta hebreo profesional, Yișhaq ben Halfün (c. 970-1020). El poema, arak galuti, está dedicado a Ibrahim ibn 'Ata y sólo se conservan unos 23 versos. ${ }^{27}$ Aunque el poema abre con la secuencia sssss, el resto de los segmentos conservados presentan una

${ }^{25}$ Según el propio 'Abdarrabbihi sólo afecta a los tres pies que comienzan por watid (wS, wSS y WLS, este último no parece viable en hebreo), consiste en eliminar la vocal de comienzo del pie y es aplicable únicamente a comienzo de verso, véase Ibn 'Abdrabbihi, Kitāb al-'Iqd al-farìd, pp. 428-429.

${ }^{26}$ Sin embargo, esta misma secuencia es catalogada por El'azar ben Ya‘ăqob (Bagdad s. XIII) como un tipo de hazağ wsS wss, uno de los más empleados en hebreo (marnin), aunque no da explicación alguna a esta variante no registrada en clásico; como ejemplo recoge el verso de un musammat que atribuye a Ibn Gabirol. Véase Yahalom, JudaeoArabic Poetics: Fragments of a Lost Treatise by Elazar ben Jacob of Baghdad, p. 88.

${ }^{27}$ Mirsky, Šire R. Yiṣhaq ibn Halfun, pp. 151-154. 
secuencia rítmica del tipo ws wss o țawīl. Tan sólo se detectan dos modificaciones: en el primer segmento del segundo verso se emplea la fórmula ss wSS (harm) y en el segundo del quinto wsSss.

Parece por tanto, que la fórmula ideada por Dunaš ben Labraț tenía la capacidad y el mérito de adaptarse a cualquier metro clásico en su versión local. ${ }^{28}$

\subsection{El siglo $X I$}

La técnica empleada por Yiṣ̣̣aq ibn Qafrūn en el s. X, dividir un único verso en cuatro segmentos dotados de autonomía métrica, puede rastrearse en algunos poemas redactados, en principio, según la normativa clásica por Ibn Gabirol. Como botón de muestra he escogido una composición que algunos suelen entender como bimétrica (alternando el poeta los metros basit y tawīl) ${ }^{29}$ y otros como una invención del propio Ibn Gabirol, ${ }^{30}$ siendo usada con cierta frecuencia por el poeta. ${ }^{31}$ El poema va dirigido a Samuel ibn Nagrela y parecía buscar impresionarle. ${ }^{32} \mathrm{Si}$ tenemos en cuenta la división del verso en segmentos dotados de autonomía, el metro del poema sería tawīl completo y con algunos segmentos afectados, de nuevo, por harm: $:^{33}$

${ }^{28}$ Para la adaptación del 'arū en Alandalus véase Corriente "Métrica hebrea cuantitativa, métrica de la poesía estrófica andalusí y 'arūd", pp. 123-132.

${ }^{29}$ Así por ejemplo, Schirmann, Ha-širah ha- iburit bi-Sfarad u-bě-Provence, p. 205.

${ }^{30}$ Según Yahalom estamos ante metros cuantitativos parciales aunque las primeras muestras (WSSSS) se catalogan como variante de tawīl. Según él, la innovación recaía en el nuevo valor del šěwa' móvil y compuesto, es decir, un valor cuantitativo. De esta manera, en la secuencia WSSSS sólo hay una vocal breve en una posición fija: a comienzo. Yahalom afirma que Ibn Gabirol, además de usar la secuencia wssss modificó el metro basīt, resultando sswss, con una licencia que le permitía introducir una breve al comienzo, wswss, sin que fuese un tawīl; en este metro no se usa tasmīt y fue muy empleado tanto en Alandalus como en los reinos cristianos. Véase Yahalom, "Re'šitah šel ha-šěqila haměduyyeqet ba-širah ha- 'ibrit', pp. 50-55.

${ }^{31}$ Hasta en siete ocasiones en la edición de Brody y Schirmann, Solomon ibn Gabirol Secular Poems. Junto con ésta, hasta en cinco ocasiones se recoge la secuencia, sswsss con $s a b a b$ añadido, en todos los casos se identifica y cataloga como basît.

${ }^{32}$ Para estos golpes de efecto véase además Ferrando, "Andalusi musammat: Some Remarks on its Stanzaic and Metrical Structure", p. 87.

${ }^{33}$ Sigo la edición de Brody y Schirmann, Solomon ibn Gabirol Secular Poems, p. 98. Existen dos traducciones del poema, la primera en Romero, Selomo ibn Gabirol, Poesía secular, pp. 122-125 y la segunda en Cano, Selomoh ibn Gabirol, Poemas, pp. 136-137. 


\begin{tabular}{|c|c|c|c|}
\hline 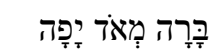 & תָתָאִיר כְּמוֹ חַָּּה & עּלָה וְנְשְׁקָפָּה & את כְּמּוֹ שַחַרר \\
\hline 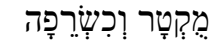 & 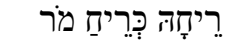 & 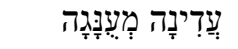 & 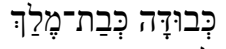 \\
\hline 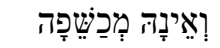 & 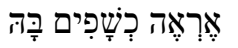 & & (1) \\
\hline 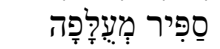 & וּבְכָל־־יקָר אֶבֶן & וִִּּינִי רְדרָלְחִים & י י זָדָבר \\
\hline 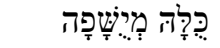 &  & 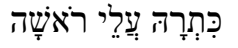 & אָהַר כִּמוֹלְדוֹ \\
\hline א אָכָכה & 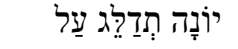 & 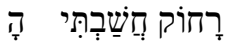 & נזה לִי מֵ \\
\hline אַפְָּּר & עַת רְאָתָה אָתִי & עַת שֶׁרְִִיתִיהָ & וֹרְרָתָּ \\
\hline כְּמוֹ עֵיפָד & וְתֵבֵל רְאִי לְוּלֵי & וְהַיוֹם דְאד כָּנְנה & ניך אָן \\
\hline 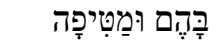 & 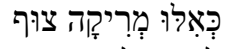 & 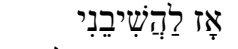 & \\
\hline רֶב & ְִהְיוֹת לְביתוֹ סוֹ & רוֹאֶה אָנִי עִוֹלָה & אוֹת שְׁמוּאֵל \\
\hline 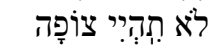 & אוֹתוֹ בְחָָּּתֵּך & 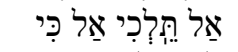 & 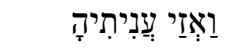 \\
\hline נִסְפָּה & 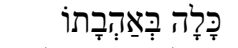 & 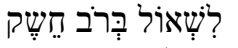 & 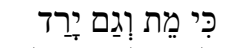 \\
\hline & שְׁממוּאֵל דָּד & שֶׁעָָׁהָה בְאַרְצֵנוּ & שְׁמוּאֵל \\
\hline שָָׁט & פְּזָרָת & כַל סוֹד סְתָרְיָָ & 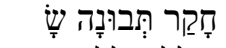 \\
\hline 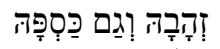 & 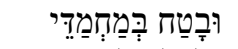 & וְכָמַס כָּאוֹצְרְוֹתָיו & לִל שְְְׁלְיָָה \\
\hline & 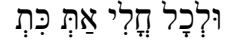 & אַתָּה צִ? & 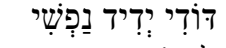 \\
\hline ון?ל? & 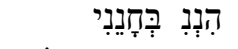 & 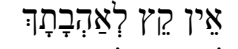 & אָד אַהַבְתִִּּך \\
\hline & יִרְרָּה דְבַר צַחוֹת & שִׁירי יְהוֹדֶף & \\
\hline וְרְפָה & אַף י-עַעטוּ בשֶׁת & 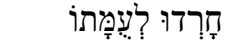 & 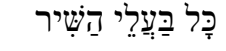 \\
\hline
\end{tabular}

Como puede apreciarse, Ibn Gabirol ya advierte en el primer verso que lo ha dividido en cuatro segmentos y que a cada uno de ellos le va a aplicar un harm, resultando una secuencia Sswss. Es en el segundo verso cuando se aclara que se trata del metro tawìl. De los 76 segmentos, 14 emplean la secuencia original wswss, mientras que los restantes 62 emplean la modificada SSWSS, que según la normativa clásica sólo puede aplicarse a comienzo del verso. Más que una innovación del poeta parece que estamos ante una realidad técnica: el verso puede dividirse en cuatro segmentos dotados de independencia métrica.

La siguiente muestra, de Yěhudah ibn Bal'am, presenta una complejidad estrófica y métrica que se aleja ya del género del musammat propiamente dicho, aunque se inspira en él y de hecho

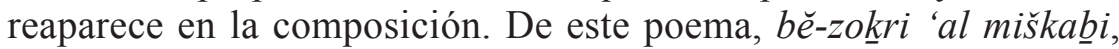
existen distintas versiones. El motivo es que se entendió como una composición sin métrica y esto provocó la alteración de lo que tuvo que ser el texto original. En este caso he seguido la edición clásica, por ser la que mejor se ajusta a la métrica original del poema: ${ }^{34}$

\footnotetext{
${ }^{34}$ Brody y Albretch, pp. 60-61. Dado que no conozco ninguna traducción al castellano de este poema, ofrezco la mía.
} 


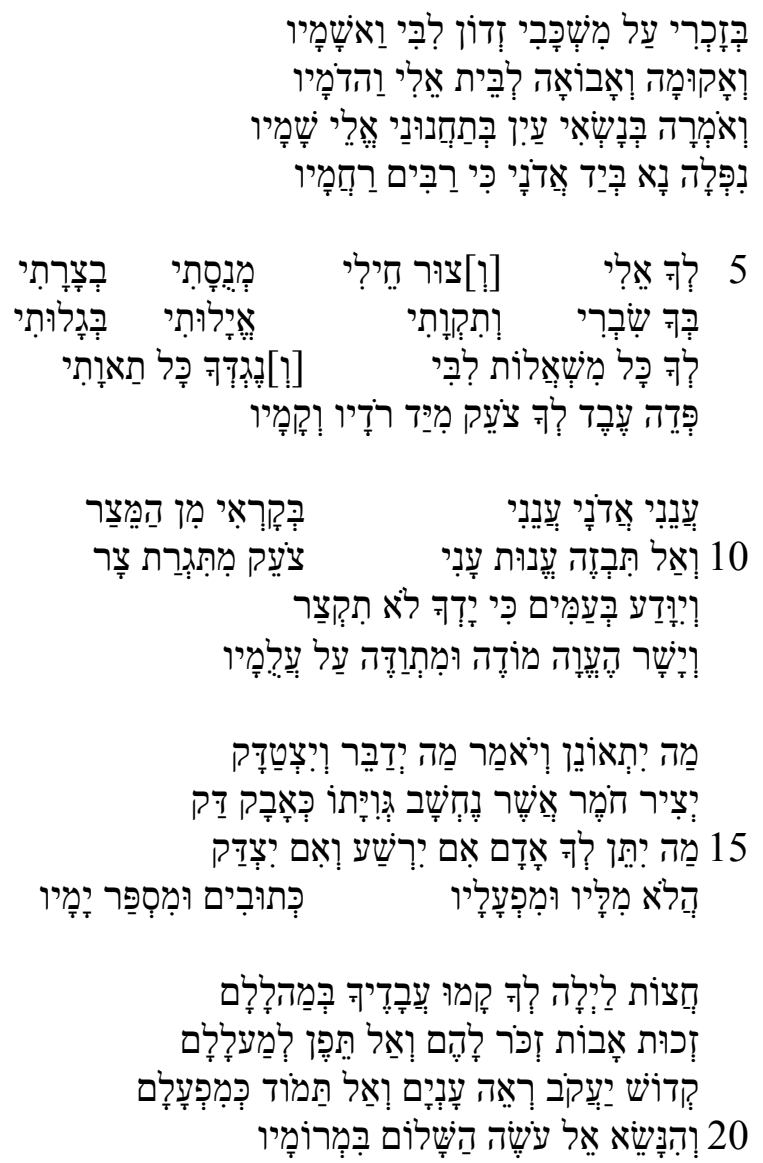

Al acordarme sobre mi lecho de la soberbia de mi corazón y sus culpas me levanto y marcho al templo de mi señor y sus aposentos.

Y digo cuando elevo la vista con mis súplicas a los cielos «mejor caigamos en manos de Dios, cuya misericordia es inmensa» $(2 \mathrm{Sa} 24,14)$

A Ti, mi Dios / Roca de mi fuerza / mi refugio / en mi angustia

En Ti, mi confianza / mi esperanza / mi energía / en mi destierro

A Ti, todas las demandas de mi corazón / ante Ti, todos mis anhelos

Redime a tu siervo que grita por el poder de sus acosadores y enemigos.

Contéstame, Señor, contéstame (1Re 28,16) / cuando invoco desde mi aprieto

No desprecies la miseria del mísero / que grita bajo el furor de la angustia

Los pueblos saben que tu mano no es corta

y el que torció el derecho, reconoce y asume sus faltas 
De qué va a quejarse y afirmar, qué va a decir y justificar Obra de barro que carece de valor, su cuerpo es cual polvo fino Qué te dará, hombre, si obra el mal o si es justo Acaso no están sus palabras y actos / escritos y el cómputo de sus días

A media noche se levantaron tus siervos con sus alabanzas La pureza de los patriarcas, recuérdalos, y no mires sus malas acciones Santo de Jacob, mira su miseria y no los juzgues según sus actos Sea alzado Dios, que hace la paz, en sus alturas

El poema compuesto por 20 versos se divide en 5 estrofas de cuatro versos cada una, lo cual queda confirmado además por el acróstico. Estas estrofas no guardan, aparentemente, relación entre sí. La primera se compone de cuatro versos, siendo el último de ellos un pasaje bíblico (2Sa 24,14$)$ que parece ser el responsable de la rima generadora que aparecerá al final del resto de las estrofas, a manera de estribillo. Su rima es simple: aaaa. La segunda estrofa comienza en forma de musammat y así se mantiene durante los dos primeros versos (vv.5-6) abandonando esta forma en el tercero, que conserva una rima interna, y añadiendo como colofón un estribillo. Su rima, sería, para cada verso, bbbb, bbbb, bb, a. La tercera estrofa abre con un versículo bíblico (1Re $28,16)$ y comienza retomando la rima del tercer verso de la estrofa anterior en el primer hemistiquio y así la mantiene de nuevo durante los dos primeros versos, desapareciendo en el tercero que sólo conserva ya la rima del segundo hemistiquio y cerrando con el estribillo; es decir, bc bc c a. La cuarta estrofa tiene forma de musammat, la innovación esta vez está en el estribillo que añade rima interna tomando la forma de un céjel; es decir, d d d aa. La última estrofa también tiene forma de musammat, pero a diferencia de la anterior, esta vez, el estribillo no tiene rima interna; es decir, e e e a.

En cuanto al análisis métrico, aunque según los editores el poema carece de metro (-- - - /-_--- ), al escandirlo según las normas del 'arū clásico el resultado que se obtiene es un hază̆ mağzu' o parcial wSS WSS WSS WSS. Siguiendo la técnica de descomponer el verso, en esta composición los segmentos se distribuyen en cuatro pies (wSS wSS WSS WSS) y a partir de ahí se aplican las modificaciones. En este caso hay seis segmentos que no computan por ser versículos bíblicos, exentos de someterse a las leyes de la métrica. Los restantes 74 se someten a la siguiente normativa: el pie dominante es WSs, hasta en 48 ocasiones; el resto han sido modificados. Las modificaciones clásicas son harm: wss se convierte en sss, hasta en 18 ocasiones; si bien, una 
de ellas podría medirse wsS si se añade una waw. En 1 ocasión aparece un pie del tipo aštar, de manera que wss se convierte en ws. Además de estas modificaciones, permitidas por la métrica clásica en este metro, hay otros dos pies, sws (4 veces; si bien, una de ellas podría medirse wSS si se añade una waw) y wsw (2 veces), aunque dada su baja frecuencia puede tratarse de un error, bien del poeta, bien de transmisión, o quizá sean formas que han sufrido modificaciones locales.

\subsection{El siglo XII}

La última muestra, yo 'eș u-meqim bi-mrom šẹhaqim de Yěhudah haLeví, ${ }^{35}$ sigue de alguna manera la tónica de las composiciones anteriores y además, supone una innovación, en este caso en su estrofismo:

\begin{tabular}{|c|c|c|c|}
\hline צִדְקוֹ סָרָח & וְועל יְם רְחוֹקִים & בִמְרוֹם שְשָָקִים & יוֹעיעץ וּמֵֵקים \\
\hline וְלְרִיק יִטְרָח & שֶֶֶׁר נִסְכּוֹ &  & 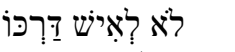 \\
\hline לְרוּץ אָרַח & יָם וְשָשׁ כְִּגבּוֹר & יוֹם רָץ בַעְעבר & עוֹלְה מִבּוֹר \\
\hline 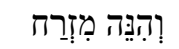 & 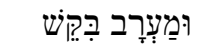 & בַּרְּּוֹ בְּמוֹקֵש & חֶטְאוֹ עִקְּש \\
\hline 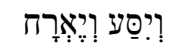 & 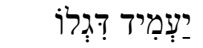 & 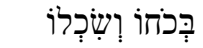 & זידַע כִּי לא \\
\hline קוֹל מַר יִצְרַח & וּמֵּרב עִבְוֹדָה & 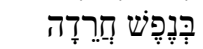 & אָז שָׁב וְהוֹדָה \\
\hline נֶיף אֶבְרָח & וְאָנָהָ ִִמָָּ & מֵרוּ חֶף & אָנָה אֵלֶּ \\
\hline עַל פְּנִי הַיָים & וְעָבְבים וְקַלִים & 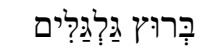 & הָמוּ גַּלּים \\
\hline וְנָשְׁאוּ דָכְיָם & וְעָלוּוּ תְהוֹמָיו & 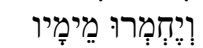 & קָדָררוּ שָשִָׁיו \\
\hline לַהְמוֹן קְשׁׁיָם & 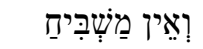 & וְקוֹל יְִִַריחַ & 10 וְסִיר יְרִתִַַַּ \\
\hline וְדָרִים חֶצְיָם & חֶצְיָם עִעָמָקִים & 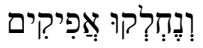 & וְרָפוּוּ דְזָקָים \\
\hline 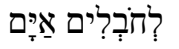 & וְועַיְן תּוֹלְה & יְרדָדה וְעוֹלְה & וְהָאָאָנִ חוֹלְה \\
\hline אַהְרַן וּמִּרִיָם & כְּעַל ַַד משֶֶה & 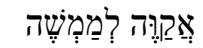 & וְלִבִי מַחְשֶֶׁה \\
\hline יְִּּיוּ: טַרח & 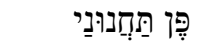 & וָאִירְא עִעָוֹנָי & אֶקְרָא אָדָנָי \\
\hline
\end{tabular}

${ }^{35}$ Brody y Albretch, $\check{S} a$ ‘ar ha-šir, pp. 97-98. La traducción, junto con una edición crítica, puede encontrarse en Sáenz-Badillos y Targarona Borrás, Yehuda ha-Levi. Poemas, pp. 476-483. 


\begin{tabular}{|c|c|c|c|}
\hline רוּּח קְצָפָּיו & 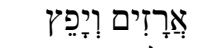 & וְקְדִים יְפוֹצֵץ & וְיָם מִתְרוֹצֵץ \\
\hline 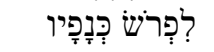 & וְנְְִָָה תָרְנָם & וְנְבְהַל סַרְנָם & שָָָׁה קַרְנָם \\
\hline 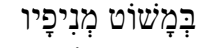 & 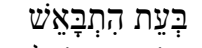 & וְלְב מִתְיָאָש & 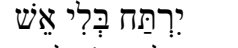 \\
\hline וְעִוְרוּים צוֹפָיו & 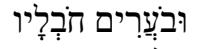 & וְנְרְִִּּים סבְרָיו & 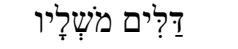 \\
\hline 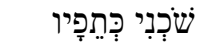 & דִּלִי הוֹן יִמְּכוֹר & 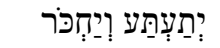 & 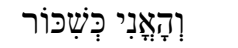 \\
\hline 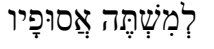 & 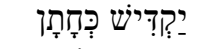 & דְּעַעד יָם אַיתָן & רוּזָה לְוְיָתָן \\
\hline וְאֶפֶס מִבְרָח & וְָָבַד מָנוֹס & תֶּאֶהַב לִכְנוֹס & רְיָם אִקְקְיָנוֹס \\
\hline שׁשי אָשִׁיבָה & 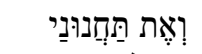 & 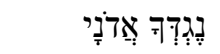 & בַּלּוּ עַינַי \\
\hline ְִף אַקְרִיבָה & 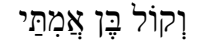 & 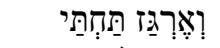 & 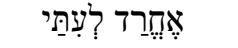 \\
\hline שְׁיר אַיטִירָה & עָרַב וְכָסוּף & אָאשֶׁר לא יָסוּף & דָּזָכְרִרי זים סוּף \\
\hline לְב אַרְחִיבָה & וּכְמוֹ רִעַדֶו & 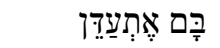 & 2 וְנוֹרְאוֹת יִרִִּּן \\
\hline וְיוֹם מֵי מְרִירָה & יוֹם אַף וְועצברָרה & 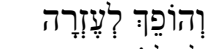 & לִמַמְמְתִּיק מָרָרה \\
\hline עַזְּים נְתִיבָה & נוֹתֵן דִּמִיִים & 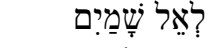 & וְהָעַינַים \\
\hline יִתיתן קָּרַח & 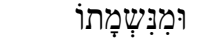 & מֵחַחָּתוֹ & חָם אַדְדָמָּוֹ \\
\hline 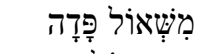 & וְאֶת נְשְׁמָתוֹ & מִבְּן אֶמָתָוֹ & הַשׁׁיב חְמָתוֹ \\
\hline וְאֵין קוֹל חַחדרָה & בַּין הַתְתמהוֹמוֹת & בַעְשׁוֹת שְׁלוֹמוֹת & 3 וְרָצוּ מְרוֹמוֹת \\
\hline וְנְסָה קְפָּדָה & וְסָרָה יְרָאָה & 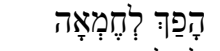 & 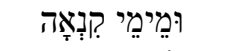 \\
\hline קוֹל הַצְעָעָדה & מִן הַקְּרוֹרְִִים & 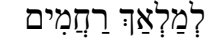 & 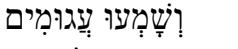 \\
\hline עָעָלִיו כָּבְדָדָה & ְוּיד צָר וּמוּיָסר & 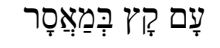 & 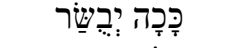 \\
\hline ִִזְמוֹר לִתוֹדָה & 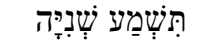 & דָדָמְתָה אָנָנָיָה & 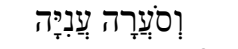 \\
\hline עָעריְּּּ זָרָח & כִִּי כְבוֹד יְיָ & 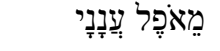 & צִאִי בַּת אֶמוּנַי \\
\hline
\end{tabular}

El poema se compone de cinco estrofas, tal y como confirma el acróstico. Cada estrofa es un musammat independiente. El último verso de la primera estrofa se configura como estribillo al romper la secuencia del musammat. La innovación consiste en que a partir de la segunda estrofa, el verso final funciona como estribillo y retoma la rima generada por la primera estrofa.

De nuevo, los editores del poema mantienen que carece de metro (-----/-----), pero al escandirlo según las normas del 'arūd clásico el resultado que se obtiene es un mutaqārib completo Ws WS WS WS WS WS WS WS. En este caso, de los 280 segmentos que componen el poema, 132 se ajustan al pie original sin modificación alguna (Ws), mientras que 135 han sufrido una modificación del tipo talm, convirtiéndose ws en SS, aunque téngase en cuenta que en este metro este tipo de modificación sólo es lícita según la preceptiva en la posición 
final del verso. En cuanto a los 13 pies restantes, 6 presentan la forma sw, quizá resultado de adaptar al hebreo la forma resultante de aplicar un tarm ( $f a$ 'lu o v); 4 la forma ww y 3 la ya conocida SSS. De nuevo, dada su baja frecuencia puede tratarse de un error, bien del poeta, bien de transmisión, o quizá sean formas que han sufrido modificaciones locales.

\section{Conclusión}

La técnica empleada en estas composiciones consiste en dividir el verso en cuatro segmentos dotados de autonomía métrica, habiéndose perdido cualquier noción de 'arụ̈ y darb. Sobre esta división en segmentos se aplica una métrica de origen clásico pero que permite la inclusión de modificaciones que parecen tener un origen local. En el siglo X, Dunaš ben Labraṭ emplea una fórmula que permite aplicar las modificaciones locales de manera libre en composiciones con forma de musammat, género en el que los metros más frecuentes son tawìl, basìt, hazağ y mutaqārib. Las primeras muestras de la segunda mitad del siglo x no son capaces de abandonar la férrea estructura del musammat, aunque se pueden presentar fórmulas polimétricas, confirmando que cada segmento es independiente métricamente hablando. En la primera mitad del siglo XI, Ibn Gabirol se atreve a aplicar esta división en segmentos sobre una casida que pretende ser clásica y sin forma de musammat. Este uso parece confirmar que la segmentación del verso era un hecho en la poesía andalusí. En la segunda mitad de esta centuria, además de mantener la segmentación y alternar el uso de licencias clásicas y locales, las estrofas irán evolucionando dentro de estas composiciones hasta adoptar la forma del céjel. Esta técnica, lejos de quedar abandonada, seguirá siendo empleada en el siglo XII por Yěhudah ha-Leví, el emir de los poetas hebreos, por lo que estuvo en boga hasta la llegada de los almohades, al menos entre los judíos.

El musammaț debió ser, de alguna manera, fácil de componer, así lo confirman los discípulos de Měnahem ben Saruq cuando critican la poesía de Dunaš ben Labraț: «Si nosotros hubiésemos querido destrozar la lengua santa como has hecho tú, hubiésemos escandido con el metro árabe nosotros y nuestros chiquillos, pero lejos de nosotros obrar así: abolir las antiguas fronteras y arrasar las viejas estructuras, 
asociarnos con gente impía que rechaza la prudencia y obstruye la justicia». ${ }^{36}$ Algo parecido parece haber en el manual de métrica que Abraham ibn 'Ezra añade en su Sefer șaḩot en el año 1145 para los judíos de Mantua, decidiendo comenzar su descripción de esta métrica por el musammat. ${ }^{37}$ Aunque el musammat puede aparecer con frecuencia en poesía secular, su presencia es mucho más común en la religiosa, este factor creo que también confirma que se trataba de una forma popular de la poesía clásica dado que el destino y consumo de este tipo de composiciones era la sinagoga.

Considero, por tanto, que a tenor de las conclusiones sobre las muestras presentadas, que son extensibles a otras muchas composiciones hebreas de la época, puede afirmarse por un lado que las muestras de musammat hebreo de los siglos X-XII se prestan o incluso derivan en juegos estróficos y silábicos inusitados, pudiendo reflejar una evolución que conduciría directamente al céjel; y por otro lado, que en la poesía hebrea andalusí no parece que existan dos modelos, uno cuantitativo y otro silábico, sino más bien, un único modelo métrico con dos registros: uno clásico que adapta escrupulosamente las reglas del 'arü otro autóctono que adapta el modelo local modificado y empleado en composiciones que suelen además prestarse a juegos estróficos.

\section{Bibliografía}

Be'eri, T., "The Phonetical-Syllabic Meter in Medieval Hebrew Poetry" (hebreo), Jerusalem Studies in Hebrew Literature, 8 (1985), pp. 50-70.

Benavente Robles, S., Tešubot de los Discípulos de Měnahem contra Dunaš ben

Labrat, edición del texto y traducción castellana, Granada, Universidad, 1986.

Brody, H. y Albretch, K., Ša 'ar ha-šir The New-Hebrew School of Poets of the

Spanish-Arabian Epoch, selected texts with introduction, notes and dictionary,

London-Leipzig-New York, Williams \& Norgate, 1906.

Brody, H. y Schirmann, J., Solomon ibn Gabirol Secular Poems, Jerusalem, The

Schoken Institute, 1974.

Cano Pérez, M. J., Selomoh ibn Gabirol, Poemas, Granada, Universidad, y

Universidad Pontificia de Salamanca, 1987.

${ }^{36}$ Těšubot talmide Mĕnahem (edición Benavente Robles, Těšubot de los discipulos de Mĕnahem).

${ }^{37}$ Edición de del Valle Rodríguez, Sefer șahot de Abraham ibn 'Ezra, pp. 146-158. 
Corriente, F., Dīwān Ibn Quzmān Alqurțubī «Ișābat al-agrāẹ fì dikr al'a 'rāḍ̂, Rabat, Dār Abī Raqrāq, 2013.

Corriente, F., Poesía dialectal árabe y romance en Alandalús, Madrid, Gredos, 1998.

Corriente, F., "Catorce cejeles de Ibn Zamrak y uno de Ibn Alxațīb (edición dialectológica, traducción y notas)", Anaquel de Estudios Árabes, 1 (1990), pp. 1-33.

Corriente, F., Poesía estrófica (cejeles y/o muwaššaḥāt) atribuida al místico granadino Aš-šuštari, Madrid, CSIC, 1988.

Corriente, F., "Métrica hebrea cuantitativa, métrica de la poesía estrófica andalusí y 'arū $\underline{d}$ ", Sefarad, 46 (1986), pp. 123-132.

Corriente, F., Gramática, métrica y texto del cancionero hispanoárabe de Aban Quzmán, Madrid, Instituto Hispano-Árabe de Cultura, 1980.

Del Valle Rodríguez, C., Sefer șaḥot de Abraham ibn 'Ezra I, edición crítica y versión castellana, Salamanca, Universidad Pontificia, 1977.

Elizur, S., "Ḥidušim bě-ḥeqer ha-širah wě-ha-piyyuṭ", en David Rosenthal (ed.), Osef ha-gĕnizah ha-qĕhirit bĕ-Genevah, qațalog u-mihqqarim, Jerusalem, Magnes Press, 2010, pp. 176-207.

Ferrando, I., "Andalusi musammat: Some Remarks on its Stanzaic and Metrical Structure", Journal of Arabic Literature, 30 (1999), pp. 78-89.

Fleischer, E., "Lě-tolědot širat ha-ḥol ha- 'ibrit bi-Sfarad bě-re'šitah", en Robert Bonfil, Menahem Ben-Sasson y Yoseph Hacker (ed.), Tarbut wĕ-ḥebrah b̆etoldot Yiśra'el bi-Yme ha-Bĕnayim: qoḅeș ma'amarim lě-ziknro šel Hayim Hilel Ben-Śaśon, Jerusalem, Merkaz Zalman Shazar lš-toldot Yiśra'el: haHebrah ha-hisțorit ha-Yiśre'elit, 1989, volumen II, pp. 197-225, [Reeditado en E. Fleischer, Hebrew Poetry in Spain and Communities under its Influence, Jerusalem, Ben Zvi Institute-Hebrew University of Jerusalem, 2010, 1, pp. 47-77].

Fleischer, E., "Lě-qadmuniot širatenu bi-Sfarad. 'Iyun ba-širim šel rabbi Mĕnahem ben Saruq", Asufot, 2 (1988), pp. 227-269 [Reeditado en E. Fleischer, Hebrew Poetry in Spain and Communities under its Influence, Jerusalem, Ben Zvi Institute-Hebrew University of Jerusalem, 2010, 1, pp. 3-46].

Fleischer, E., "Běhinot bě-'aliyat šițot ha-šĕqila ha-měduyaqot ba-šira ha- 'iḅit", Leshonenu, 48.2-3 (1985), 142-162.

Fleischer, E., "Contributions hébraïques a une meilleure compréhension de quelques aspects de la poésie européenne du haut moyen age", Settimane di Studio del Centro Italiano di Studi sull'Alto Medio Evo, 26 (1980), pp. 815866.

Fleischer, E. "Mibnim sțrofiyim me‘ayin ezurim ba-piyyut ha-qadum”, Ha-sifrut, 2 (1970), pp. 194-240. [Reimpreso en E. Fleischer, Hebrew Poetry in Spain and Communities under its Influence, Jerusalem, Ben Zvi Institute-Hebrew University of Jerusalem, 2010, 1, pp. 119-195]. 
Ibn 'Abdrabbihi, Abū 'Umar, Kitāb al-'Iqd al-farīd, edición de Aḥmad Amīn et alii, Cairo 1948.

Martínez Delgado, J., "El uso de la métrica árabe en la obra Ben Tehillim de Samuel ibn Nagrela”, Sefarad, 72, 2 (2012), pp. 263-294.

Mirsky, A. Šire R. Yiṣhaq ibn Halfun, Jerusalem, Bialik Institute, 1961.

Romero, E., Selomo ibn Gabirol, Poesía secular, colección Clásicos Alfaguara, prólogo de Dan Pagis, selección, traducción y notas, edición bilingüe, Madrid, Alfaguara, 1978.

Sáenz-Badillos, A., "Los discípulos de Mĕnaḥem sobre la métrica hebrea", Sefarad, 46 (1986), pp. 421-431.

Sáenz-Badillos, A., Tešubot de Dunaš ben Labraț, edición crítica y traducción española, Granada, Universidad y Universidad Pontificia de Salamanca, 1980.

Sáenz-Badillos, A., Yehuda ha-Levi. Poemas, colección Clásicos Alfaguara, introducción, traducción y notas, estudios literarios de Aviva Doron, Madrid, Alfaguara, 1994.

Sáenz-Badillos, A. y Targarona Borrás, J., Poetas hebreos de al-Andalus (siglos $x$-xii). Antología, Córdoba, El Almendro, 1988.

Sánchez Sancha, A., "Introducción exegética a la métrica tradicional árabe", Awraq Yadida, 7-8 (1984-85), 47-173.

Schippers, A., "Secular Hebrew Poetry in Muslim Spain till 1225 - A General Overview with the New Tendencies, Problems", Iberia Judaica, 1 (2009), pp. 119-134.

Schirmann, J., Ha-širah ha- 'ibrit bi-Sfarad u-bĕ-Provence, Jerusalem-Tel Aviv, Bialik Institute-Devir, 1959.

Varela Moreno, M. E., Těšubot de Yěhudit ben Šešet, edición, traducción y comentario, Granada, Universidad y Universidad Pontificia de Salamanca, 1981.

Yahalom, J., Judaeo-Arabic Poetics: Fragments of a Lost Treatise by Elazar ben Jacob of Baghdad, Judaeo-Arabic text and Hebrew translation (hebreo), Jerusalem, Ben-Zvi Institute, 2001.

Yahalom, J., "Re’šitah šel ha-šěqila ha-měduyyeqet ba-širah ha- 'ibrit", Leshonenu 47, 1 (1983), pp. 25-61.

Recibido: $17 / 10 / 2014$

Aceptado: 29/09/2015 